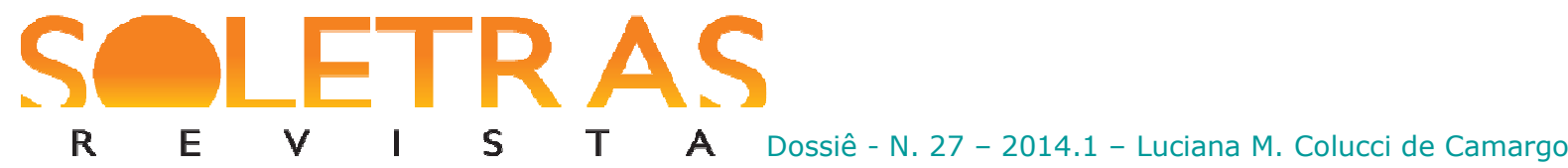

\title{
The Tutu, morals of the Fin de Siècle: recepção e conjecturas acerca de um romance decadentista sob os signos fatais do dandismo e do espaço gótico
}

\author{
Luciana Moura Colucci de Camargo ${ }^{1}$ \\ Universidade Federal do Triângulo Mineiro
}

Resumo: Este ensaio analisa a obra The Tutu, Morals of the Fin de Siècle (1891), atribuída ao escritor e editor francês Léon Genonceaux (1856-1905?), a partir de seu diálogo entre a estética decadentista e a gótica. Sob o viés dos signos fatais do Decadentismo - o dandismo, a androginia e a artificialidade como simulacro - The Tutu narra as aventuras excêntricas do jovem dândi Maurice Noirof em busca de sensações raras que afrontam os "códigos" sociais, religiosos e sexuais vigentes em Paris ao final do século XIX. Por sua natureza decadentista, ainda apresenta um tom macabro. The Tutu suscita naturalmente o diálogo com o Gótico e, portanto, valoriza o espaço como relevante para sua estrutura narrativa. É justamente da peculiar ligação de Noirof com o espaço que surge uma atmosfera soturna e lúgubre em que o medo, a angústia, o monstruoso e a busca por experiências exóticas da personagem definem o enredo. Portanto, o conjunto dessas injunções estéticas, formais e temáticas frisa a relevância de The Tutu para a contemporaneidade, justificando assim um estudo mais aprofundado desta narrativa, considerada pela crítica uma das obras mais estranhas, misteriosas e fascinantes já escritas, a "sort of ultimate decadent novel", nas palavras de Genonceaux.

Palavras-chave: The Tutu. Decadentismo. Dândi. Gótico. Espaço.

Reputedly 'the strangest novel of the nineteenth century', this most peculiar book was lost for over 100 years. Sub-titled MORALS OF THE FIN DE SIĖCLE, it was written under the pseudonym of PRINCESS SAPPHO, and it is presumed to be the work of LEON GENONCEAUX (GENONCEAUX, 2013, capa).

The circumstances of the composition of Le Tutu, so partially known, (...) do not explain much about it, except circumstantially. Genonceaux appears to have attempted to write the "decadent novel" to end all decadent novels (GENONCEAUX, 2013, p. 13, grifo do tradutor).

\section{Introdução}

Este ensaio crítico discute a controversa obra The Tutu, morals of the Fin de Siècle

\footnotetext{
${ }^{1}$ Professora adjunta do Departamento de Estudos Literários da Universidade Federal do Triângulo Mineiro (UFTM), em Uberaba (MG). Graduada em Letras - Português / Inglês, pelo Centro Universitário Moura Lacerda (1996); mestre e doutora em Estudos Literários pela Unesp / Araraquara (2002 e 2006). Tem experiência na área de Letras - Ensino, Pesquisa e Extensão, com ênfase em Literaturas Estrangeiras Modernas (Inglesa e NorteAmericana), atuando principalmente nos estudos relacionados ao modo fantástico e suas vertentes. Adicionalmente, leciona a disciplina de Literaturas Africanas de Expressão de Língua Portuguesa. Possui relevante experiência na área de gestão universitária: de 2008 a 2012 foi responsável pela coordenação administrativa e pedagógica da Central de Idiomas Modernos (CIM). De 2008 a 2013 coordenou os trabalhos da Comissão Própria de Avaliação Institucional (CPA). Integrou a equipe de implantação da área de internacionalização na UFTM.
} 
$\begin{array}{llllllll}R & \text { E } & \text { V } & \text { I } & \text { S } & \text { T } & \text { A } & \text { Dossiê - N. 27-2014.1-Luciana M. Colucci de Camargo }\end{array}$

(1891) a partir de seu entrecruzamento estético, uma criação literária finissecular que suscita um diálogo "maldito" entre o Decadentismo e o Gótico. Atribuída ao escritor e editor francês Léon Genonceaux (1856-1905?), que a publica no outono de 1891 sob o significativo pseudônimo de Princess Sappho, The Tutu misteriosamente "desaparece" antes mesmo de sua distribuição chegar às livrarias.

Por seu enredo subverter com irreverência os padrões sexuais, morais, religiosos e políticos da malograda sociedade burguesa do final do século XIX, acredita-se que Genonceaux tenha recolhido as cópias de The Tutu do mercado por temer uma possível prisão, uma vez que já estava sendo acusado pela publicação de textos imorais dos enfants terribles Rimbaud (1854-1891) e Lautréamont (1846-1870). Após esse episódio, o nome de Genonceaux novamente é envolvido em questões policiais, visto que a ele também é imputada a publicação do texto erótico Hémine (1890), de Jean Larocque cujas cópias foram confiscadas.

Portanto, acredita-se que conjuntamente esses fatos contribuíram para que The Tutu não tenha "circulado" no meio literário na época de sua publicação, pois, como coloca White, "it would certainly have been unwise to put out a book which was not only obscene, but also blasphemous, under the circumstances" (GENONCEAUX, 2013, p. 12). As especulações acerca dos fatos que envolvem essa obra são tão enigmáticas que ironicamente até seu autor também "desaparece", sendo que desde 1905 não se tem mais notícias sobre ele. Com o desaparecimento de Genonceaux, as possibilidades de se traçar precisa e historicamente a gênese de The Tutu ficam prejudicadas.

\section{Recepção e fortuna crítica}

Genonceaux appears to have been intent on outraging just about everyone, and The Tutu is gleefully Nietzschean in its dismemberment of contemporary morality. It is simultaneously a sort of "ultimate decadent novel" and outlandishly modern; it is also repellent, infatile and deeply cynical. Yet despite all its absurdities and extravagances, in the it somehow manages to appear compassionate, poetic, funny...and even - most absurdly of all - rational (GENONCEAUX, 2013, contracapa).

Se a atmosfera em torno de Genonceaux, da possível existência de um manuscrito com suas memórias, da publicação e do súbito desaparecimento de The Tutu é nebulosa, a recepção e os estudos críticos especializados sobre tal obra também não parecem ser diferentes. Da publicação em 1861 até a tradução, empreendida por Iain White, para a língua inglesa em 2013, The Tutu percorre um caminho repleto de hiatos e silêncios que corroboraram para que este "estranho" romance não aderisse à história da literatura e aos SOLETRAS, N. 27 (jan.-jun. 2014) 
$\begin{array}{llllllll}\text { R } & \text { E } & \text { V } & \text { I } & \text { S } & \text { T } & \text { A Dossiê - N. 27-2014.1-Luciana M. Colucci de Camargo }\end{array}$

estudos literários nem, tampouco, salvo engano, circulasse amplamente no âmbito acadêmico.

Após ficar "perdida" por praticamente cem anos, The Tutu é "redescoberta" em abril de 1966 em um artigo de Pascal $\mathrm{Pia}^{2}$ (1903 - 1979) para a La Quinzaine Littéraire. Primeiramente, observa-se que Pia retoma o crítico Maurice Saillet para explicar que o mesmo, em seu ensaio de 1954, dedicado aos inventeurs de Maldoror, valoriza sobremaneira a figura do editor Léon Genonceaux pelo mérito de ter republicado, em 1890, o texto de Lautréamont intitulado Les chants de Maldoror e, em 1891, sob o título de Reliquaire, poesias de Rimbaud:

Dans l'essai historique et critique qu'il consacrait en 1954 aux inventeurs de Maldoror, Maurice Saillet a très exactement mis en valeur l'importance de découvreur exceptionnel que fut à l'époque du Symbolisme, l'éditeur Léon Genonceaux. Sans doute cette importance avait-elle échappé à la plupart des contemporains de Genonceaux. Les amateurs éclairés n'ont jamais constitué une foule très dense, et tout porte à croire que les lecteurs habituels de Zola, de Daudet, de Maupassant, de Bourget et de Loti ne prêtèrent guère d'attention aux deux coups de maître que Genonceaux accomplit en moins d'un an : d'abord en décembre 1890, en rééditant Les Chants de Maldoror, puis en novembre 1891, en réunissant pour la première fois, sous le titre de Reliquaire, les poésies d'Arthur Rimbaud (PIA, 1966, p. 1).

Após enfatizar a proeza de Genonceaux em publicar, com menos de um ano de diferença esses textos, Pia assinala a possível existência de um manuscrito de memórias do controverso editor que foi leiloado na Bélgica em 1948 e cujo comprador nunca foi identificado:

Il existerait, paraît-il, des mémoires de Genonceaux dont le manuscrit aurait été vendu vers 1948, par un libraire de Bruxelles, à un amateur qui jusqu'à présent ne s'est pas fait connaître. Si cela est exact, il est regrettable que ces mémoires demeurent inédits. Outre les détails piquants qu'on y trouverait peut-être sur les démêlés de Genonceaux avec la police et la magistrature, ils nous offriraient vraisemblablement de quoi résoudre le petit problème d'histoire littéraire que pose un curieux ouvrage, intitulé: Le Tutu, moeurs fin de siècle (PIA, 1966, p. 2).

Tal manuscrito também revela detalhes picantes da vida de Genonceaux e sua conturbada relação com a polícia, os tribunais e os credores. No entanto, o que de fato desperta a atenção nesse excerto é a menção de Le Tutu, moeurs fin de siècle, a que Pia se refere como sendo uma curieux ouvrage e relata seu encontro acidental com a mesma:

Le hasard seul m'a fait découvrir ce roman, édité par Genonceaux dans les derniers mois de 1891, et dont l'auteur se dissimule sous le pseudonyme de

\footnotetext{
${ }^{2}$ Em sua tradução de The Tutu, Iain White, menciona, em nota de rodapé, que Pascal Pia, nascido Pierre Durand, é "um órfão da Grande Guerra, autodidata, poeta e estudioso literário; jornalista; lutador ativo na Resistência; editor de Apollinaire, Baudelaire, Cros e Lautréamont; especialista em livros proibidos e em fraudes literárias; patafísico" (2013, p. 08, tradução nossa, grifos do tradutor). 


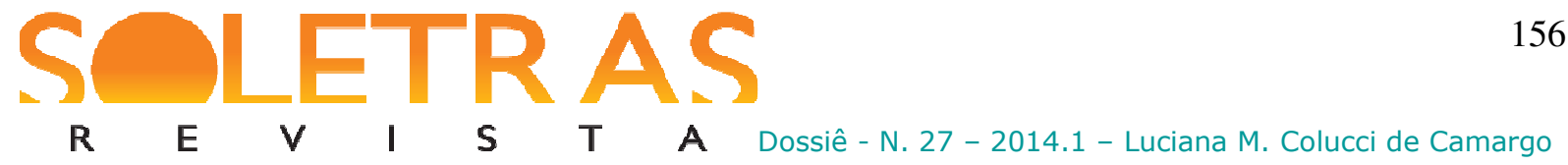

Princesse Sapho. La Bibliothèque Nationale n'en possédant pas d'exemplaire, il n'est pas inutile de préciser qu'il s'agit d'un de ces in-16 de format courant qui, durant un demi-siècle environ, se sont débités au prix marqué de 3 F 50 (PIA, 1966, p. 2).

O fato de Pia ter cruzado com Le Tutu por acaso não é surpreendente, visto que, como ele próprio ressalta, à época, a Biblioteca Nacional não possuía sequer um exemplar de The Tutu. Não obstante, White defende que tal situação não é mesmo inusitada, já que, até o momento, somente cinco cópias da primeira edição são conhecidas, sendo que nenhuma delas se encontra em biblioteca. White explica ainda que "one of these copies lacks a cover, and another has scrawled on its title-page the inscription: 'Dégoutant, à brûler' - 'Disgusting, to be burnt'." (2013, p. 9).

No excerto acima, ainda há uma questão importante a ser destacada, a vinculação da autoria dessa "obra curiosa" a Genonceaux que, ao publicá-la em 1861, opta pelo sugestivo pseudônimo de Princesse Sapho, na grafia francesa. Ao longo do restante do artigo, Pia dedica-se a sustentar as razões pelas quais ele acredita ser mesmo Léon Genonceaux o autor de Le Tutu, moeurs fin de siècle. Deste modo e considerando que Pia era um expert em livros proibidos e fraudes literárias, não parece restar dúvidas sobre a autoria desse romance decadentista publicado somente um ano após Oscar Wilde (1854-1900) ter chocado a sociedade vitoriana inglesa com o emblemático The picture of Dorian Gray (1891).

Além do mais, cabe frisar, sobre a importante ligação entre Pia e Le Tutu, que o crítico realmente estava fascinado pela escritura e possibilidades estéticas dessa obra, visto que se esmerou em redatilografá-la visando a sua publicação. Mesmo com inúmeras tentativas, Pia não obteve sucesso e faleceu sem "ver" sua "descoberta" ressurgir das cinzas finisseculares do século XIX.

No entanto, em 1991, doze anos após a morte de Pia e por ocasião do centenário de Le Tutu, a pequena editora Tristam Mayenne apresenta esse romance para o público. Após um novo silêncio de dezessete anos, a mesma editora em 2008 reimprime Le Tutu com um posfácio de Jean-Jacques Lefrère intitulado 'Quel livre étrange'. Em seguida, em 2009, o romance é publicado em Barcelona (El Tutú) com prefácio do escritor espanhol Juan Goytisolo (1931).

Por fim, em 2013, é publicada para a língua inglesa com tradução, introdução e notas de Iain White. Na introdução, White faz considerações sobre a origem, autoria, recepção e desaparecimento de The Tutu (doravante The Tutu). Há dois instantes interessantes nas reflexões de White, sendo o primeiro quando há uma breve discussão sobre o 
$\begin{array}{llllllll}\text { R } & \text { E } & \text { V } & \text { I } & \text { S } & \text { T } & \text { A } & \text { Dossiê - N. 27-2014.1-Luciana M. Colucci de Camargo }\end{array}$

entrecruzamento estético presente em The Tutu que o coloca em franco diálogo com as ficções popular e científica, o romantismo, o simbolismo e o decadentismo. Inclusive, ao comparar The Tutu com The picture of Dorian Gray, White atesta que "the contrast could not be more striking" (2013, p. 13). Mas, a meu ver, o peculiar encontra-se justamente no início da introdução, quando há uma aproximação entre The Tutu e Ulysses (1922), de James Joyce (1882-1941), no sentido de sugerir, mesmo hipoteticamente, que Joyce pode ter tido algum contato com essa obra:

There are things it would be more pleasant to believe...though there are limits to credibility. All the same, the wish - or perhaps the possibility persists...In Ulysses, we read of how Stephen Dedalus, summoned from Paris for his mother's funeral, brought back with him 'Rich booty [...] Le Tutu, five tattered numbers of Pantalon Blanc et Culotte Rouge'. Whether or not Joyce might have known, seen or heard of the book Le Tutu is still - just about - an open question [...] But then again, Joyce was a voracious and omnivorous reader, and well acquainted with French fin-de-siècle writing...There are things it would be pleasant to believe...

However, Joyce's knowing of this book would have made him quite unique. For a long time, indeed until its centennial republication in 1991, Le Tutu could have been described as the book that almost never was. (GENONCEAUX, 2013, p. 7).

Possibilidade concreta ou ainda a ser desvendada, The Tutu: the book that almost never was, apresenta elementos que a aproximam da estética modernista, visto que, como Ulysses, muitos tipos textuais - vinhetas de teatro, carta, uma partitura musical curiosamente intitulada The twilight of the flesh (Music by God, Lyric by The Word) - aparecem ao longo de seus capítulos, proporcionando ao leitor uma experiência estética bastante desafiadora, inclusive em relação a experimentos com a linguagem, que se estende também ao seu eixo temático. Toda essa gama de estratégias motivou White a referir-se à criação de Genonceaux como 'half crazy' book in which he crashed together almost every known literary genre (...) what effect would it have had if it had indeed appeared in 1891, when it was written?" (GENONCEAUX, 2013, p. 14).

Estendendo esse "desconforto" à recepção e à fortuna crítica de The Tutu, à parte os estudiosos citados anteriormente, não há ao que nos parece, até o momento, outros estudos críticos realizados sobre essa obra half crazy. Ressalva-se, no entanto, que, durante pesquisa bibliográfica, encontramos o texto Le silence du texte: poétique de la décadence, publicado em 2003, em que o pesquisador Jean de Palacio (2003, p. 39-40) discute The Tutu:

Hors de la poésie, qui semble le laboratoire normal pour de Telles experiénces, une pratique romanesque se fait jour avec La publication, em 1891, d'um etrange roman intitule Le Tutu. Mouers fin de siècle, sous La signature <<Princesse Sapho >> (peut-être l'éditeur Léon Genonceaux, qui 


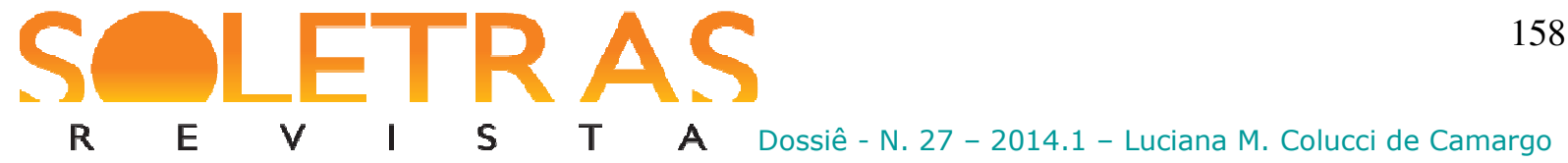

avait reedite Lautréamnt l'année precedente). Yl y a d'aulleurs um mystère autour de ce livre, $<<$ découvert $>>$ par Pascal Pia et peut-être apocryphe. Le héro, Mauri de Noirof, posséde sur le language des ideés particulières: $<<$ Il est bien fâcheux que l'on n'ait pas encore trouvé le moyen d'abréger de langage. Pourquoi ne proncencerait-on pás seulement la première syllable des mots pour aller plus vite?

Nesse excerto, Palacio discorre sobre o protagonista Maurice Noirof (Mauri) em um momento da narrativa em que essa personagem "conversa" utilizando somente a primeira sílaba de cada palavra. Com tal episódio, o crítico explica que a metáfora da perda parcial da palavra por um processo de mutilação ou segmentação é a continuação lógica da analogia estabelecida pelo crítico Bourget entre o corpo e a linguagem. De forma perspicaz, Palacio ilustra essa reflexão citando outro episódio de The Tutu, em que Mauri é comparado a uma guilhotina humana em miniatura.

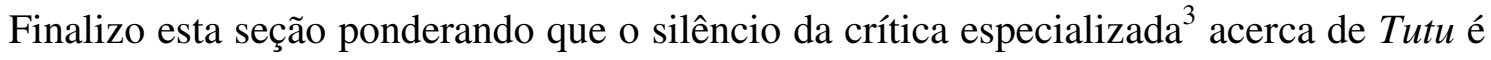
perturbador e nos leva a refletir se esse "silêncio" é devido à própria estranheza de sua validade literária ou à sua circulação ainda - salvo engano - restrita no meio acadêmico. De uma maneira ou de outra, essas indagações corroboram para que The Tutu permaneça em uma espécie de limbo literário. Quanto à resposta, bem o tempo dirá ou, nas palavras de Palacio (2003, p. 1) no prefácio de Le silence du texte: "Il y a temps pour tout. Temps pour écrire, et temps pour ne plus écrire. Temps pour parler, et temps pour se taire".

\section{Decadentismo: a estética da "encruzilhada"}

Don't make fun of politics. Nowadays, if you haven't been a minister or something similar then you're a nobody (...) We have the good fortune - or the misfortune, if you prefer - to be witnessing the end, the dying moments of a century in such a state of mental feverishness as will never be surpassed. Let us rejoice. (GENONCEAUX, 2013, p. 124, 2013).

A publicação na Inglaterra do manifesto romântico Lyrical ballads (1798) anuncia uma revolução artística no século XVIII, sedimentado nos ideais "clássicos" de razão, luz e engessamento da poesia, para dar vazão a um novo posicionamento estético "libertador" nos âmbitos formal e temático. Conforme os poetas Wordsworth and Coleridge, da Lake School,

\footnotetext{
${ }^{3}$ Em pesquisa eletrônica via Internet sobre The Tutu deparamo-nos com algumas páginas de blogs, propagandas de livrarias, uma página na rede social Facebook ("entrada" na rede datada de 13 de julho de 2009 e última postagem datada de 01 de fevereiro de 2010). Ademais, há uma referência em uma página bastante interessante denominada Writers no one read em que se pode ler: "Marc Lowenthal of Wakefield Press writes about a new publication from Atlas Press: Princess Sappho / Léon Genonceaux's The Tutu (1891), "the strangest novel of the nineteenth century". Acesso em 30 de maio 2014, disponível em http://writersnoonereads.tumblr.com.

SOLETRAS, N. 27 (jan.-jun. 2014) ISSN: 2316-8838

DOI: $10.12957 /$ soletras.2014.11785
} 
$\begin{array}{llllllll}R & \text { E } & \text { V } & \text { I } & \text { S } & \text { T } & \text { A } & \text { Dossiê - N. 27-2014.1-Luciana M. Colucci de Camargo }\end{array}$

já anteciparam no advertisement do manifesto, "Readers of superior judgment may disapprove of the style in which many of these pieces are executed. It must be expected that many lines and phrases will not exactly suit their taste" $(1798$, p. 1) - tal atitude realmente não agradou aos poetas doutrinários da Age of Reason.

É nesse contexto de vozes "superiores" e racionais que o campo artístico assiste então a eclosão do movimento romântico cujo alicerce, moldando-se desde a Renascença, funda-se na ascensão da burguesia, na (re) visão estética das artes, e na concepção de um "eu" individual. Diante desse cenário, o elo entre razão e emoção suscita a liberdade da forma e da essência, trazendo à tona a "harmonia dos contrários" em que as máscaras apolínea e dionisíaca corroboram para a visão totalitária do homem no sentido de compreendê-lo como um ser contraditório par excellence.

Nessa passagem repleta das contradições românticas, o século XIX caminha e adiante presencia a burguesia em pleno poder, provocando mudanças revolucionárias ainda mais intensas nas esferas artística e social. No âmbito social, os ecos da Revolução Francesa (1789), a herança inglesa das Revoluções Industriais (entre 1760 e 1840) e do Crystal Palace (1851), construído majestosamente para albergar a Great Exhibition of the Works of Industry of all Nations, ainda influenciam uma burguesia embevecida com as novidades do "mundo moderno" e com o signo do progresso alicerçado nos avanços científico e tecnológico.

No entanto, tantas mudanças culturais, estéticas e sociais praticamente "simultâneas" não trazem somente o lado feérico da expansão dos horizontes, assim o indivíduo do entrecruzado século XIX vivencia os momentos de angústia e ansiedade de um mundo cada vez mais voltado para a materialidade. Com a percepção de que o processo civilizatório e a vida citadina podem ser uma ilusão perversa, o homem ainda precisa conviver com a ideia de uma possível queda de sua origem divina. Mediante essa circunstância crítica, o século XIX experimenta uma crise finissecular, pois as expectativas de um bom viver, clamadas por um coro de vozes revolucionárias e chanceladas pelo culto ao progresso, são suplantadas por um intenso mal-estar. O fin de siècle abre, portanto, em termos de estética literária, passagem para um "novo ismo", o Decadentismo. Para o estudioso Latuf Isaias Mucci (1990, p. 30-31), esse movimento parte

[...] de um contexto, onde se esvaziaram todos os ideais humanitários do Romantismo e em que se firmava uma civilização utilitária, o sentimento obsessivo de decadência conduziu a uma revolta contra todos os valores, princípios e dogmas religiosos ou racionalistas, tornando-se o Decadentismo "a expressão literária do anarquismo" [...] Estética da encruzilhada, o Decadentismo construiu-se tremulamente sobre a indecisão, a imprecisão, a 


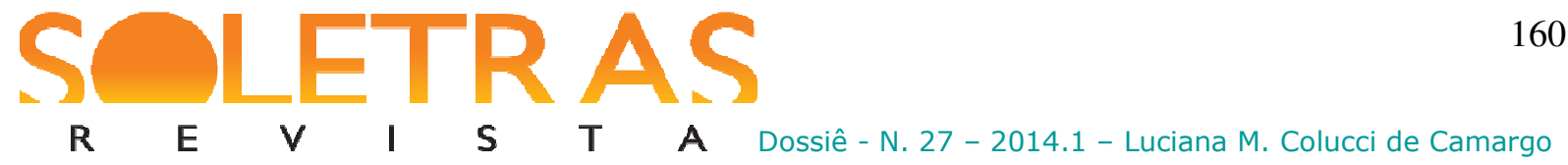

vaguidade de um homem encurralado entre a aristocracia em derrocada e a burguesia, a meio caminho entre o mundo antigo e clássico e o mundo tecnocrata e moderno.

Em tessitura ora de aproximação, ora de afastamento e ora de subversão com o Romantismo, o Realismo, o Naturalismo e o Simbolismo, o Decadentismo configura-se, portanto, como essa estética "da encruzilhada" que, embora baseada na ideia de "decadência", não permite que sua arte fosse vista como envilecida. Ao contrário, como "Fênix, a arte ressurgia triunfante das cinzas finisseculares" (MUCCI, 1990, p. 30) para libertar o homem como um "todo", nas múltiplas e caleidoscópicas esferas que circundam sua relação do "eu" com os universos físico e psíquico.

Sob esse prisma, algumas figuras fulcrais como Schopenhauer (1788-1860), Hartman (1842-1906), Nietzsche (1844-1900) e os poètes maudits, Poe (1809-1849), Baudelaire (18211867), Huysmans (1848-1907), Rimbaud (1854-1891), Laforgue (1860-1887), D’Annunzio (1863-1938), Wilde (1854-1900) e, agora, Genonceaux (1856-1905?), bem representam o espírito "indomável” e gótico do artista decadente com seu culto da arte pela arte e seu eterno desprezo pela humanidade burguesa, pragmática e utilitarista. Ou como diz Balzac (2012, p. 31-32):

O artista é uma exceção: sua ociosidade é um trabalho e seu trabalho, um repouso; ele é. Alternadamente, elegante e desleixado; veste, a seu belprazer, a camisa do operário, e decide-se pelo fraque trajado pelo homem da moda; não está sujeito a leis: ele as impõe. [...] O artista é sempre grande. Ele tem uma elegância e uma vida próprias, porque nele tudo reflete a sua inteligência e a sua glória. Tantos quantos forem os artistas, tantas vezes as vidas caracterizadas por ideias novas. Neles, a fashion não deve ser imposta: esses seres indomáveis moldam tudo a seu gosto. Se tomam posse de um símio é para transfigurá-lo.

Essas vozes, associadas a tantas outras e, notadamente, a de Paul Bourget (1852-1935, com seu ensaio Théorie de la décadence, 1881) e de Anatole Baju (1861-1903, autor do Manifesto do Decadentismo, 1886), lapidam a estética decadentista (1880-1890) que se firma por meio de estratégias textuais que Mucci poeticamente define como uma "trindade, não santíssima, mas artificialíssima: o dandismo, a androginia, a artificialidade como simulacro" (1990, p. 48). Neste momento, partindo de uma dessas estratégias - a esfíngica figura do dândi -, prossigo com a análise do objeto deste ensaio, The Tutu, morals of the Fin-de-Siècle, sob a perspectiva do dândi Mauri e sua predileção pela espacialidade gótica.

\section{Maurice de Noirof: fulgurações de um dândi}




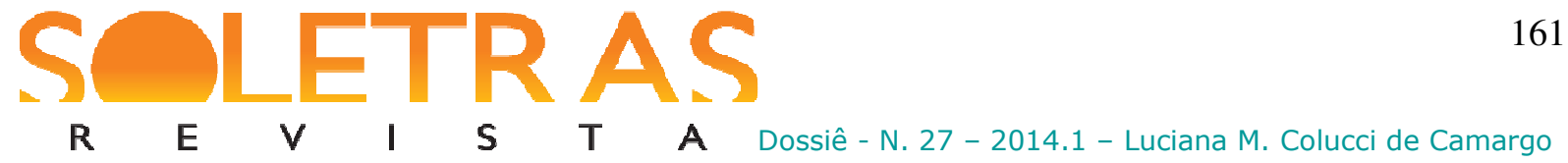

Figura singular, o dândi, assumiu, no Decadentismo, outra postura além da caracterizada ou caricaturada pelos dicionários, enciclopédias e jornais, embora possa ter mantido um aspecto exterior estranho e provocante. $O$ modelo do dândi finissecular busca-se em Baudelaire, que poetizou a tragédia da existência, criando um dandismo filosófico e literário. Trágico, fatal, o novo dândi - o dândi do fim do século - beira os abismos (MUCCI, 1990, p. 50).

Considerada a filha bastarda de Huysmans e Artaud, The Tutu narra as excentricidades do jovem esteta Mauri que, tomando por lema que a humanidade turned to jelly (GENONCEAUX, 2013, p. 112), vive (des) aventuras peculiares pelas ruas de Paris finissecular em que a moralidade moderna em esferas diversas é ridicularizada. Para satisfazer sua ânsia hedonista e narcísica, o protagonista subverte quaisquer sistemas preestabelecidos, códigos de ética e de civilidade, pois encarna, como dito na epígrafe, o signo fatal do dândi finissecular à beira dos abismos.

Logo no início da narrativa, Mauri, em típica atitude de um flâneur, passeia aleatoriamente pela cidade, por volta das cinco horas da manhã, observando tudo a seu redor, bem como pensando em assuntos de naturezas diversas como castidade, casamento, eletricidade e exploração de minas quando percebe que precisa voltar para casa. Na verdade, Mauri está "desaparecido" há um mês e, em seu retorno, é confrontado por sua mãe, Madame de Noirof:

"Oh, my child, how you stink! And that get-up! What's come over you: You haven't shown your face for a month. I've been worried. I went to the police. What have you been getting up to in Valence?"

"In Valence?"

And she showed him a police report referring to his visit to Valence a fortnight previously.

"And with a woman, what's more? And a great fat woman, at that! God! Is it possible? And you so well brought up!".

He protested. The report was untrue. He hadn't left Paris.

(...) I slept with her for I don't know how many days; then I slept with the big black one from the Marais; then I slept with Gigette."

And he counted them out on his fingers - he's bedded eighty-two women, in a month! His mother listened entranced, drinking his words.

"You must be mistaken, Mauri, just think now, eighty-two women!"

He went over the figures and came to a total of ninety-eight and half. (GENONCEAUX, 2013, p. 41-42).

Ao chamar Mauri de "my child" e observar seu estado físico ("how you stink"), a mãe demonstra sua angústia com o sumiço dele, acreditando, inclusive, que ele estava em outro país, na Espanha, como o jornal anuncia. Ao recuperar-se do susto, seu comportamento se modifica e ela mostra-se indignada com o fato de o relato policial ainda inferir que ele estava acompanhado de uma mulher gorda. Nesse momento, ela ressalta que aquela situação não está 
$\begin{array}{llllllll}R & \text { E } & \text { V } & \text { I } & \text { S } & \text { T } & \text { A } & \text { Dossiê - N. 27-2014.1-Luciana M. Colucci de Camargo }\end{array}$

em conformidade com a educação esmerada ("And you so well brought up") que o filho recebeu. Ao explicar-se, Mauri desmente a estória policial e narra tranquilamente suas aventuras sexuais durante o mês em que esteve "desaparecido", sendo que, ao relembrá-las, conta que havia dormido com um total de noventa e oito (e meia) mulheres.

Tal comportamento da personagem não é surpreendente visto que sua natureza, lapidada nas searas decadentista e baudeleriana, evidencia o dandismo como sendo uma instituição “à margem das leis, tem leis rigorosas a que são estritamente submetidos todos os seus adeptos, quaisquer que forem, aliás, a audácia e a independência de seu caráter" (BAUDELAIRE, 2006, p. 870).

Essa independência do caráter de Mauri e sua incapacidade para o "outro" são tão latentes que no decorrer da narrativa há vários instantes em que a personagem explicita de forma entediada seu repúdio ao humano, "I detest the human race" (GENONCEAUX, 2013, p. 63). Revela-se, portanto, uma personagem que manipula tudo de acordo com o próprio desejo, sendo que o "outro" realmente só lhe importa enquanto um meio para que a satisfação de suas vontades sejam elas confessáveis ou não.

Ademais e ainda como uma instituição às margens das leis, Mauri encontra-se em constante peregrinação em busca de experiências e sensações "raras" que sugere uma maneira não só de saciar seus desejos, mas uma forma de repudiar o senso comum e ordinário dos burgueses parisienses. Para a personagem, o "comum” é desprezível, pois afinal a educação sentimental recebida de sua mãe foi para que Mauri justamente se elevasse à condição de "homem superior":

She took him by the hands, gazed into his eyes, then thrust him away. "If you're deceiving me, you'd better watch out. I adore you because you're not in the least like other men. You're unbalanced, you don't understand that your nature is superior to that of others. Resembling the commom run of men is but an irony of fate. Remember one thing, and that is that life is only a Sensation, and that is ought to be an Extraordinary Sensation. There is no after life. The soul is no more than the ferment of matter. Off you, you're troubling me. You make me happy" (GENONCEAUX , 2013, p. 42).

Essa citação, uma continuidade da conversa em que Mauri conta suas peripécias sexuais à mãe no mês em que ficou "desaparecido" - e as quais ela ouvia "entranced, drinking his words" (GENONCEAUX, 2013, p. 42) -, ressalta a adoração que ela nutre pelo filho, explicando que por ser a vida apenas uma sensação a mesma precisa ser uma "extraordinary sensation”. Com o intuito de justificar esse pensamento, e provavelmente fazendo alusão aos 
$\begin{array}{llllllll}\text { R } & \text { E } & \text { V } & \text { I } & \text { S } & \text { T } & \text { A Dossiê - N. 27-2014.1-Luciana M. Colucci de Camargo }\end{array}$

pressupostos de Allan Kardec (1804-1869) e à doutrina espírita ${ }^{4}$, cunhada no controverso século XIX, ela argumenta que não existe vida após a morte e a alma nada mais é do que um fermento para a matéria.

Além dessas reflexões ontológicas sobre a condição da existência humana, é importante atinar sobre o emprego do termo "sensação" (sensation), pois o dândi, como já dito anteriormente, constrói seu percurso alicerçado na busca por sensações raras, podendo perpassar o exótico e até mesmo o inusitado. Desta maneira, ao dândi é incorporada uma figura de linguagem divinizada pelos Simbolistas: a sinestesia. Mais uma vez, estamos diante de um caminho que se envereda pelo entrecruzamento estético entre o Simbolismo e o Decadentismo, já que o dândi é como a árvore frondosa que, no bosque simbolista baudelairiano, vê passar os mortais seguindo-os apenas com o olhar.

Nessa seara, Mauri é uma personagem que se realiza inteiramente por meio da sinestesia e dos gradientes sensoriais ${ }^{5}$ (visão, tato, paladar, audição, olfato), visto que essa é sua forma de apreensão do mundo e de buscar situações incomuns e, até mesmo, grotescas. Como bem reflete Ackerman, "o mundo é um manjar saboroso para os sentidos [...] não há uma maneira de compreender o mundo sem detectá-lo antes com o radar dos sentidos" (1992, p. 13). Assim, por meio dos gradientes sensoriais, o protagonista transgride todas e quaisquer fronteiras limítrofes da ética e, divagando sobre a "human stupidity and the universal law of hypocrisy" (GENONCEAUX, 2013, p. 47), deleita-se com relações sexuais, alimentos, bebidas e toda gama de "grotesqueries" totalmente repulsivas ao "homem comum" burguês.

No decorrer da obra, há um encadeamento sucessivo dessas "grotesqueries" como é o caso do episódio em que o leitor é surpreendido, logo ao início da narrativa, com a descrição física da personagem "Mani-Mina" que, por meio de uma construção imagético/sinestésica, surpreendente é apresentada como uma "aberração" da natureza tanto que a mesma está se apresentando no Hippodrome:

For a month he (Mauri) was in the grip of a passion for a monstrosity being exhibited at the Hippodrome: it was a woman with two heads, four legs and four arms; she had a single pelvis and just one stomach; they called her Mani-Mina $[\ldots]$ one evening, after a very successful performance, he $[\ldots]$

\footnotetext{
${ }^{4}$ Em vários momentos da narrativa, o Cristianismo é alvo de ironia e sarcasmo, inclusive há uma passagem em que o médico-cientista Dr. Messé-Malou afirma que "there is no God. Man is the Creator" (2013, p.101).

${ }^{5} \mathrm{Na}$ obra Espaço \& Literatura: introdução à topoanálise, o autor, Ozíris Borges Filho, explica que os gradientes sensoriais são relativos aos sentidos humanos: visão, audição, olfato, tato e paladar. Para o estudioso, é por meio dos sentidos que o ser humano se relaciona com o espaço e "efeitos de sentido importantes são manifestados nessa relação sensorialidade-espaço" (2007, p. 69). Os gradientes sensoriais são uma das etapas de análise da Topoanálise cujo objetivo é desenvolver uma analise minuciosa da construção espacial na literatura e em outras artes.
} 


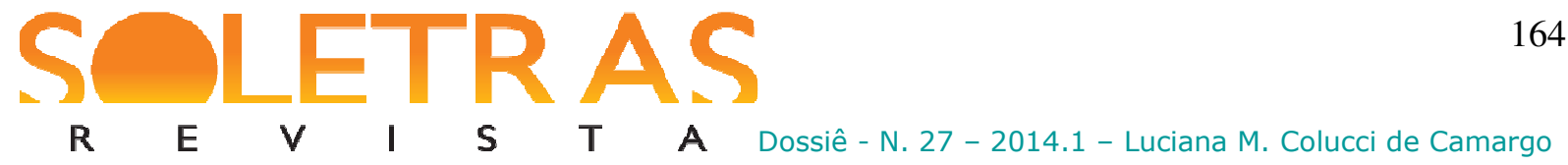

invited her to supper [...] The prospect of a night of love unique of its kind tickled Mauri's fancy deliciously; he made improper suggestions; one said yes, the other said no [...] When this freak of nature was undressed, Mauri had a moment of hesitation. Should he bed it? This strange body, joined below the waist, had only one spinal column: naked it resemble two flayed calves, back to back on a butcher's slab. The skin was pale - apart from Mina's, which was mottled with red blotches. Two very distinct odours issued from the body, an odour of decay, and one of fresh meat, an odour of life and one of death. The mixture was nauseating. To possess such a being bordered on desencration, but the unexpected attraction overcame Noirof's scruples; however, he had an atrocious night (GENONCEAUX, 2013, p. 59-61).

Embora hesitante à visão da nudez daquele corpo grotesco ("it was a woman with two heads, four legs and four arms; she had a single pelvis and just one stomach"), Mauri, em sempre experiências inusitadas para o tédio dos tempos ("The prospect of a night of love unique of its kind tickled Mauri's fancy deliciously"), sucumbe e se torna "responsável" pela iniciação sexual da "criatura" (monstrosity being). Ao observar (visão) o corpo desnudo de Mani-Mina, Mauri descreve o odor (olfato) que o mesmo exala de sua parte física como sendo, em Mina, uma espécie de decomposição e, em Mani, um de carne fresca. Sob outro prisma e considerando a parte simbólica, uma exala o cheiro da vida e, a outra, o da morte. Toda essa circunstância sensorial e social não detém Mauri que mediante a extraordinária situação de possuir algo tão bizarro passa "por cima" de seus escrúpulos e se lança a uma noite frenética. ${ }^{6}$

O frenesi provocado por essa experiência sexual bizarra é tão entorpecente que Mauri fica com Mani-Mina por um mês se esquecendo, inclusive, de seu casamento com Hermine, uma jovem rica que vem acompanhada de um bom "dote". Em nenhum momento, Mauri demonstra qualquer tipo de apreço em relação à futura esposa. Para ele, Hermine não passa de uma jovem obesa, alcoólatra e que tinha o hábito de devorar filamentos retirados do interior de suas narinas, bem como soltar flatulências.

Já casado, Mauri recebe em casa a visita de Mani-Mina para comunicar a notícia de que está grávida de um filho dele. Estarrecido com a notícia, Mauri cria outro contexto absurdo e Mani-Mina passa a morar com ele e a esposa, tendo, inclusive, o consentimento de sua mãe (Madame de Noirof) e de sua sogra. Chegada a hora do parto, mais uma vez, o leitor é

\footnotetext{
${ }^{6}$ As "grotesqueries" são inúmeras ao longo da narrativa. No entanto, a que se evidencia como mais estranha está na cena final de The Tutu quando Mauri e sua mãe mantém relação sexual sobre o caixão da falecida Hemine: "The train moved off. In silence their eyes, their wild eyes settled upon the coffin placed on the seat opposite them. They were alone. They understood each other. Abruptly, he seized her and bent her over the coffin. She abandoned herself. He abandoned himself. They abandoned themselves. And they knew each other in a long, impure and hideous embrance..." (GENONCEAUX, 2013, p. 168). 
$\begin{array}{llllllll}\text { R } & \text { E } & \text { V } & \text { I } & \text { S } & \text { T } & \text { A Dossiê - N. 27-2014.1-Luciana M. Colucci de Camargo }\end{array}$

surpreendido com uma cena grotesca, pois o bebê tem quatro cabeças, oito braços, oito mãos e é "metade" masculina, "metade" feminina. Ao dar à luz, a parturiente falece e tal fato leva à passagem que relata o momento em que Madame de Noirof e Mauri se banqueteiam com o cérebro de Mani-Mina. Para ressaltar ainda mais a natureza estranha de The Tutu, é Mauri quem amamenta a criança, pois havia feito um tratamento para produzir leite paterno: "Mauri had only two breasts but his progeny had four mouths" (GENONCEAUX, 2013, p. 126).

Essas circunstâncias - forma monstruosa, hibridismo, corpo deformado - associadas ao “absurdo, bizarro, macabro, depravado, degenerado e perverso" (EDWARDS; GRAULUND, 2013, p.01, tradução nossa) definem o que em lato sensu se denomina grotesquerie e, no caso de deformidades corpóreas, grotesqueria excessiva como apontam Edwards e Graulund (2013, p. 02). Observa-se que essa sorte de grotesqueries forma a base constitutiva das experiências e sensações de Mauri e, por sua vez, são construídas por meio de cenas dicotômicas: atração e repugnância como no momento em que ele hesita para ter relações sexuais com Mani-Mina, mas, no entanto, a atração pela "novidade" é mais forte e ele cede a tal ponto de ficar com ela por um mês. Sobre a conflitante ambivalência grotesca entre atração e repulsão, Edwards \& Graulund postulam:

The grotesque provokes conflicting responses: fascination and repugnance, compassion and disgust, sympathy and confusion. Grotesque bodies might rouse disgust and/or attraction insofar as they offer insights into the limits of the body and human experience. Authors, artists, and filmmakers have long celebrated the strange body as a site of production: its repulsive qualities can be attractive to those seeking modes of transgression that challenge normative forms and behaviours. In this, the grotesque is disturbing because it incites seemingly incompatible emotions through its representations of abjection and possibility, limitations and becomings, compassion and rejection, attractions and repulsion $(2013$, p. 78$)$.

A ânsia de Mauri por novidades é tanta que ele e sua mãe dividem um projeto secreto como é o caso da bebida chamada sputum ${ }^{7}$ e da carne do cérebro de Mani-Mina:

But they were in a hurry to see their secret project through: with a saw they made cross-cuts in both skulls and extracted the marrow. Mani's smelt good, but the other stank like carrion.

"Let's eat that one quick," said Madame de Noirof. "I could eat a horse."

But because they weren't able to drink any of their sputum while they were eating they suffered from indigestion and spewed up Mina's brain. After that, they ate again what each had just vomited up, and felt no further upset. (GENONCEAUX, 2013, p. 129).

\footnotetext{
${ }^{7}$ Sputum, em Português: escarro, expectoração. Mauri e sua mãe apreciavam muito beber asthmatic sputum. Em The Tutu, a bebida é composta por "decayed lungs, and in which greenish phlegm, white mucus and red saliva" (2013, p. 125). 


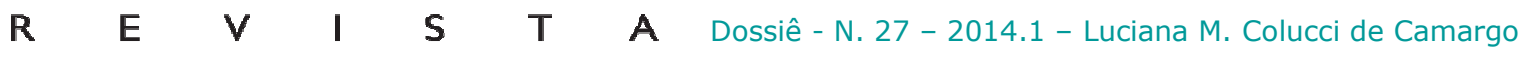

Nessa citação, Mauri conversa com sua mãe porque a mesma havia falsificado dinheiro para adquirir uma peça de antiguidade (um bidet todo rebuscado) e precisa da ajuda do filho, que nesse ponto da narrativa é um Ministro, para se livrar das acusações. A conversa é logo interrompida porque eles estão ansiosos para prosseguir com o projeto sinistro e grotescamente absurdo: abrir o crânio de Mani-Mina para comer seu cérebro e beber sua "seiva". Em uma espécie de ritual de celebração, eles pegam um serrote, abrem o crânio delas e degustam a "iguaria" em atitude de deleite absoluto. No entanto, ao constatarem que a porção cerebral de Mina está podre, acabam vomitando. E a única coisa que lamentam e não ter nenhuma garrafa de Sputum para auxiliar na digestão. Mas, logo em seguida, ao comer o próprio vômito, a sensação de mal-estar passa. Esse ato de comer órgãos do interior de um corpo grotesco e morto (cadáver) e de beber sua "seiva" implica ainda uma leitura baseada no canibalismo e na necrofilia. A leitura dessa passagem certamente provoca repugnância no leitor, no entanto, ao se tratar de um dândi, tal situação é "normal" e se configura como um traço de uma diferença às avessas na arquitetura textual de Mauri. E aqui retomamos o texto de Ackerman quando a estudiosa explica que paladar é uma questão íntima e apresenta variação de uma cultura para outra e o modo como gostamos das coisas é "algo tão individual como nossas impressões digitais" (1992, p. 156).

Mesmo que a história da humanidade registre inúmeros casos de apreciação de carne humana (como é o caso dos Celtas na Inglaterra e de algumas tribos americanas), essa circunstância "bizarra" denota um rompimento brutal com quaisquer limites que definem as fronteiras entre um "eu civilizado" e um "eu não civilizado". Inclusive é importante pensar que os conceitos da "civilização" em relação a muitas esferas que envolvem o homem são moventes. Para esclarecer mais a esse respeito, Ackerman, ainda abordando o tema do paladar, comenta que o Doutor William Kitchner, no The Cook's Oracle, cita uma receita grotesca de um cozinheiro chamado Mizald de preparo e degustação de um ganso ou um pato vivo (1992, p. 177, grifo da autora). E a receita, contida em detalhes no livro da estudiosa, é aterrorizante visto que o modo de preparo da ave é descrito como um ato violento e cruel. Ainda acrescento que, de acordo com a receita, esse ato é acompanhado de voyeurismo mórbido, já que os degustadores precisam acompanhar atenciosamente o sofrimento da ave para não deixá-la morrer e, com isso, encontrar o "ponto" exato da carne. No entanto, no que se refere à carne humana, há "consenso" no sentido de ser considerada como tabu. Assim, ao final, o que realmente importa não são os fatos em si, mas os prazeres sensoriais que eles provocam. Tanto é esse o sentido que a mãe de Mauri, em um momento de "bate-papo" com 
$\begin{array}{llllllll}\text { R } & \text { E } & \text { V } & \text { I } & \text { S } & \text { T } & \text { A } & \text { Dossiê - N. 27-2014.1-Luciana M. Colucci de Camargo }\end{array}$

ele, diz "(n)obody will ever guess at the sublimities hidden within our hearts [...] Let us act so that we might die in the satisfaction of having experienced, we alone, the True Sensation" (2013, p. 121).

\section{O espaço gótico como traço da escritura decadentista}

É principalmente pelo viés do gótico que se dá o liame entre o Romantismo e o Decadentismo [...]. O gótico literário de fins do século XVIII e começo do século XIX é um estilo que, mais do que nenhum outro talvez, caracteriza-se pela atmosfera aterrorizante, pelo cenário e pela decoração (...), que lhe conferem um caráter de teatralidade e simulacro (BARROS, 2010, p. 130).

O século XX dedicou-se ao tempo. Sob o signo de uma nova era marcada pelo ritmo acelerado do século precedente, esse elemento da estrutura narrativa instaurou na literatura um movimento de interiorização da personagem como uma espécie de escapismo da balbúrdia moderna, principalmente após as revoluções industriais. Por meio de estratégias textuais como o fluxo de consciência, a literatura moderna volta-se para as experiências subjetivas, pois o mal-estar do sujeito frente a um contexto bélico é cristalino e profundamente vivenciado do "lado de dentro". Deste modo, a sucessão temporal linear e cronológica se torna um recurso literário "obsoleto" saindo de cena para dar lugar ao tempo psicológico.

No entanto, como a arte de maneira geral movimenta-se em constante processo de reflexão sobre si mesma, a teoria contemporânea das últimas décadas tem revisitado o estudo acerca da categoria do espaço enquanto elemento bastante significativo nas artes, principalmente na literatura. Com investigações teórico-literárias postuladas por estudiosos como Joseph Frank (1945), Maurice Blanchot (1955), Henri Lefèbvre (1974), Iuri Lotman (1978), Jean-Yves Tadié (1979), Gaston Bachelard (1989), Fredric Jameson (2002), Ozíris Borges Filho (2007), entre outros, evidencia-se que no contexto artístico contemporâneo o espaço tem sido revalorizado, sendo deslocado da margem para o centro e fazendo com que inúmeras obras literárias também sejam revisitadas com o intuito de percebê-las sob o prisma da construção espacial. E este é o caso das literaturas de vertente romântica (em sua porção gótica) e decadentista como bem aponta Barros na epígrafe desta seção.

Exatamente por sua natureza estética da "encruzilhada", o Decadentismo volta-se para o contexto romântico/gótico capturando seu forte sentimento de mal du siècle e de um indivíduo rebelde, mórbido e desconfortável frente a uma vida mediana. Com isso, lapida-se uma personagem que se posiciona no texto como um verdadeiro ídolo, "cultivando e cultuando um 


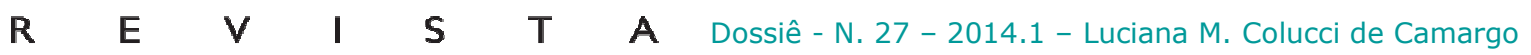

individualismo aguçadíssimo, um egotismo herdeiro, sem dúvida, do culto do gênio da aurora do século XIX" (MUCCI, 1990, p. 36). Da ideia desse ídolo entediado plasma-se a concepção do dândi decadentista que se comporta como um "habilíssimo decorador", como explica Mucci quando se refere à obra Il Piacere (1889), de D’Annunzio (1863-1938):

Os objetos de decoração, no texto dannunziano, posicionam-se como signos, ao mesmo tempo que se constituem em fortaleza para a solidão do protagonista, uma torre de marfim art noveau, competindo com a torre de Babel ao querer atingir o infinito da beleza. O universo íntimo de Sperelli povoa-se de rosas especiais, jarras de cristal, taças preciosas, tapetes, cortinas, almofadas, espelhos, peças de arte, colecionadas por um 'habilíssimo decorador [...] que fez de sua casa um 'perfeitíssimo teatro' (1990, p. 36).

Dessa maneira, o dândi imbrica-se de forma homológica ao espaço vivido de maneira que personagem e espaço tornam-se praticamente extensão um do outro. No entanto, essa ligação se dá sob o "signo do artifício" (BARROS, 2010, p.130), da construção de um paraíso artificial à moda baudelairiana com um toque requintado de Poe (1809/1849) e sua The Philosophy of furniture (1840) na qual é possível observar que o autor dedica bastante atenção à estruturação do espaço nos moldes góticos como explica Camargo:

[...] Nesse texto [A filosofia do mobiliário - 1840], Poe, descreve, sem perder a ironia e a crítica ferina que lhe são peculiares, um aposento ideal em termos de espaço, incluindo a decoração (mobiliário), a atmosfera e, como não poderia deixar de ser, uma personagem aristocrática, erudita e, geralmente, em profundo transtorno físico e psíquico. $\mathrm{Na}$ verdade, Poe, seguindo a tradição gótica inglesa e dos contos românticos alemães German Tales - constrói uma poética do espaço gótico que ele aplica racional e objetivamente em seus contos e poemas os quais privilegiam esse elemento da estrutura narrativa sobre essa face gótica (2008, p. 3-4).

É nesse paraíso artificial que o dândi, em movimento de fuga da plebe ignara, encastelase e corporifica sua "torre de marfim" em que "cada item do mobiliário (móveis, quadros, espelhos, livros, cortinas, tapetes, flores, entre outros) trazem à cena a atmosfera gótica, soturna, outonal e, por fim, misteriosa dos grandes clássicos do gênero" (CAMARANI e CAMARGO, 2014, p. 28). Justamente é esta situação que temos em The Tutu e que passamos a analisar agora iniciando por uma passagem em que Mauri e sua futura esposa, Hermine, escolhem a mobília para sua casa:

A discussion then arose on the subject of furniture, Mauri wanted Italian, Hermine wanted Breton.

- "Oh!" she exclaimed, "those Breton tables from Landivisiau and SaintThégonnec, those carved rustic cupboards from Pont-Aven and the PontAven box-beds, you're so comfy in them (...).

She gazed at him with her big, beautiful eyes, all overflowing with goodness, which pierced deep into his inmost self. 


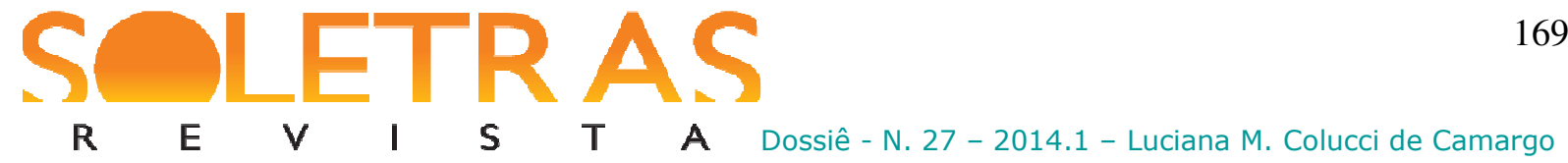

"A box-bed? To suffocate in? Thanks very much! Ah, Italian furniture, that's the only sort. It's stylish, it's light, it's all skies and sunlight."

But he realized that the inclinations of this fat little woman were wholly directed towards ugly and massive objects. Furthermore, Madame Israël raised an objection to which he was obliged to submit:

"Blue skies and sunlight, that's not very solid. Can you see Hermine sitting in a chair made of blue skies and sunlight? The chair would break in no time [...]"

So they purchased a suite of Breton furniture. Mauri de Noirof took a secret pleasure in selecting the most tasteless, the most cumbersome, the squattest and the dreariest; he set his heart upon rustic pieces, the most down-to-earth, the most rugged, put together by rural carpenters and upon which a clumsiness of workmanship, and coarseness and naïveté of conception imprinted a seal of frozen hideousness (GENONCEAUX, 2013, p. 57-58, grifo nosso).

Nesse excerto, percebe-se que o léxico furniture é repetido algumas vezes de modo a despertar a atenção do leitor e demonstrar a ligação que Mauri tem com cada detalhe do espaço, principalmente no que tange ao mobiliário. Essa ligação é tão vital que no decorrer da narrativa o espaço e sua decoração cada vez mais se tornam presente e fulcral para traduzir o refinamento estético de Mauri. Ao perceber que não consegue convencer Hermine a comprar italian furniture, ele desiste, mas, "por dentro", ao referir-se a ela como "fat little woman were wholly directed towards ugly and massive objects", não deixa de destilar sua porção de "escarnário e mal dizer" pelo gosto da noiva para a mobília, revelando sobremaneira que esse casamento já estava começando de maneira equivocada. ${ }^{8}$

Embora Mauri tenha se referido à mobília italiana como sendo light e all skies and sunlight, sua predileção pelo goticismo é logo revelada e chancelada pelo excerto a seguir:

Mauri Noirof had succeeded in acquiring some of the exhibits produced in the course of the trial: the famous trunk, in which the perfumes and fine linen had been packed; the cord she wore around her waist; the sack, used for the dust-sheet of the easy chair in whose arms she settled her divine figure; the pulley, set in motion by trying a gingerbread man to it as a counterweight. To make the scene of the crime more authentic Mauri obtained some pig's blood and spattered it over the walls and the floor. Skulls and bones adorned the ceilings in the different rooms, and on a gloomy day, dark as the Conscience of Mankind, the apartment would resemble a tomb. They experienced the height of intoxication on visiting the place every Friday and on the thirteenth of each month. Mauri arrived first; he drew the shutters and lit the green-glass lamps, which hung down from dried human intestines. That done, he laid the table and set on their favourite dish: a plate of decaying brain taken from a body dissected in the

\footnotetext{
${ }^{8}$ Tal fato clarifica-se na narrativa, pois Mauri aceita se casar com Hermine somente por causa do dote. Ademais, em várias passagens é evidente o desprezo que ele, e também sua mãe, sente por ela. Inclusive, há uma passagem em que Madame de Noirof deseja a morte da nora: "So make her die; get her to eat fatty, starchy food; one day she'll choke to death, and that will be our salvation. The only thing in the world that matters is us (GENONCEAUX, 2013, p. 120-121).
} 


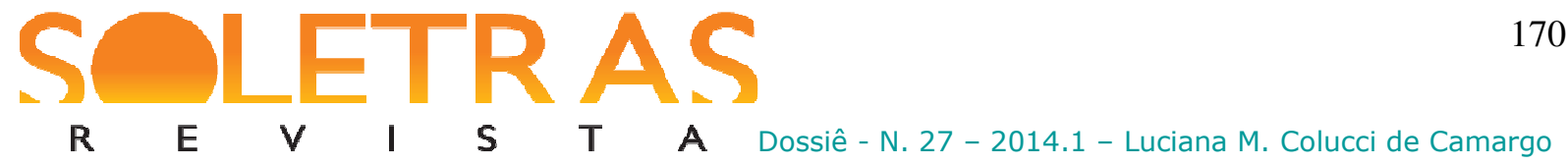

amphitheatre at the Medical School; they spread it thinly on some bread and ate a lot. They washed down their meal with an excellent bottle of vintage asthmatic sputum, harvested in hospitals. They then delighted in reading from Les Chants de Maldoror; they deranged aspect of this work, a blend of brilliant insanity and insane genius, set the tone for their time together. Mauri declaimed, in a voice from beyond the grave, the following stanzas, of which they never tired (GENONCEAUX, 2013, p. 116, grifos nossos).

Nesta "cena", observa-se que Mauri, com o atento olhar de "habilíssimo decorador", vislumbra moldar o apartamento de maneira análoga a um sepulcro. Com tal imagem em mente, a personagem tem o "capricho" de comparecer a um julgamento com o único intuito de adquirir um baú com objetos (linen, perfumes) ${ }^{9}$ retirados da cena de um crime real no contexto diegético para que justamente o ambiente, por meio da estratégia de simulacro, possa alcançar um efeito de real.

Para consubstanciar ainda mais a cena do crime, Mauri adquire também sangue de porco, ossos e caveiras para ornamentar os ambientes do apartamento para que de fato, como dito acima, se parecesse com um túmulo ("and on a gloomy day, dark as the Conscience of Mankind, the apartment would resemble a tomb"). O desejo pelo noturno, sombrio e macabro é tão evidente que as green-glass lamps estão dependuradas por meio de intestinos humanos. Entretanto as grotesqueries, como já analisadas na seção anterior, apresentam-se novamente com o intuito de acentuar ainda mais a atmosfera assustadora do apartamento, bem como falar sobre o paladar deles. Assim, Mauri prepara um banquete que "combina" com o espaço. Temos, então, "a plate of decaying brain taken from a body dissected in the amphitheatre at the Medical School [...] an excellent bottle of vintage asthmatic sputum, harvested in hospitals". O esmero é tanto que a garrafa de asthmatic sputum obviamente não é "comum", é, para acentuar ainda mais o clima de refinamento e elegância, vintage.

Aqui é possível refletir que a relação de Mauri com o alimento não é aquela herdada da era industrial que pensa o alimento apenas "como um combustível para o corpo" (ACKERMAN, 1992, p. 198). Ao contrário, por sua condição de esteta, a atitude de Mauri

\footnotetext{
${ }^{9}$ Por pertencerem a uma mulher falecida, o linho e os perfumes suscitam uma aura feminina, delicada e sensual, evocando por extensão uma imagem muito cara aos românticos: a da mulher morta como uma divine figure. Ademais, essa mesma imagem de feminilidade ainda parece se converter em um signo notoriamente decadentista: a androginia. Considerando o título que Genonceaux escolhe para seu romance decadentista - The Tutu - essa associação parece realmente fazer sentido já que "tutu" corresponde à saia delicada de tule usada pelas bailarinas. Nas aventuras de Mauri pela casa de La Pondeuse, ele veste o traje de bailarina - tutu - porque quer aprender alguns passos de ballet. Inclusive, a capa da primeira edição de Le Tutu é justamente o desenho de Mauri vestido com o tutu. Nas notas da introdução de White, ele explica que a capa do livro "with its inappropriate gaiety (i)ts in fact, a pastiche of the cover of a pseudonymous work by Brunhoff, Paris sur scène by Guy de Saint-Môr [...] The episode involving the tutu in the book evidently had a hidden meaning that Brunhoff would $[\ldots]$ have appreciated. The pseudonym of Sapho [...] remains a mistery, however, in a book singularly devoid to lesbianism!" (GENONCEAUX, 2013, p. 12). 
$\begin{array}{llllllll}R & \text { E } & \text { V } & \text { I } & \text { S } & \text { T } & \text { A } & \text { Dossiê - N. 27-2014.1-Luciana M. Colucci de Camargo }\end{array}$

sugere um "papel" de gourmet, um "experimentador nato", buscando na gastronomia, na bebida, na decoração, na música e na satisfação do desejo carnal uma forma de vivenciar a vida além dos limites preconizados pela sociedade burguesa da época. Apesar de haver uma ética para as coisas da vida e da relação do indivíduo com o mundo, existe uma camada da vida e da dimensão psicológica do homem que é cinzenta e é justamente nessa dimensão cinzenta que Mauri habita ou seu sobrenome não seria Noirof criando um jogo com o léxico francês noir que, em português, como adjetivo, significa negro, preto. Já no nível figurado, esse adjetivo amplia seu significado podendo ser traduzido como sombrio ou tenebroso.

E, obviamente, para ressaltar a porção erudita de um dândi, a literatura não pode deixar de estar presente: Mauri se delicia com Les chants de Maldoror. Esses elementos, perfeitamente concatenados entre si, dão vazão ao simulacro de paraíso artificial ${ }^{10}$ "mauriciano", pelo viés de um efeito de sentido gótico e estranho, que ajuda a personagem a se isolar, tal qual Des Esseintes, a "bíblia" do Decadentismo, "do incessante dilúvio da parvoíce humana" (HUYSMANS, 1987, p. 36-37).

Em outro momento da narrativa, o leitor mais uma vez é confrontado com mais uma passagem bizarra: a degustação de um gato de rua (tomcat) que foi encontrado morto na rua:

They dragged in behind them an old, dead tomcat, tied to a cord, all stinking, viscious and magotty. Found in the gutter at three, or rather three eighteen in the morning. The women were liquored-up and, for a lark, made as if to chuck the cat somebody's head, a joke enjoyed by all present.

"Let's make it into a stew, it's nice and gamy!"

But the old-slap-in-the-gob artist protested - it would be better eaten cold. When they asked him which piece he'd like best, he replied, in a voice as flaccid as his cheecks:

"The unmentionable bit."

And, because they thought he was having them on:

"Really though, the unmentionable bit! That's the best part in animals, and above all in cats, even more so in dead cats, and most of all in a worm-eaten dead cats. Oh! To eat that dainty! Or not to eat it..."

It was decided they should toss a coin to see which of the three women should proceed with the ablation of the thing in question [...] Again La Pondeuse was chosen. An enormous and very sharp butcher's knife was brought in on a pewter dish; the rotting carcass was laid on the floor between four burning candles, they formed a circle around it, then champagne glasses were raised and all intoned a pious chant:

This is now Mary's month, Of all the months the fairest.

[...] "Let me have the tail then, just a bit, a tiny little bit of fifty centimeters, no more than that".

\footnotetext{
${ }^{10}$ Note-se que esse apartamento é visitado por Mauri em uma data muito específica e carregada de carga simbólico-religiosa, toda sexta-feira e todo dia 13 de cada mês. 


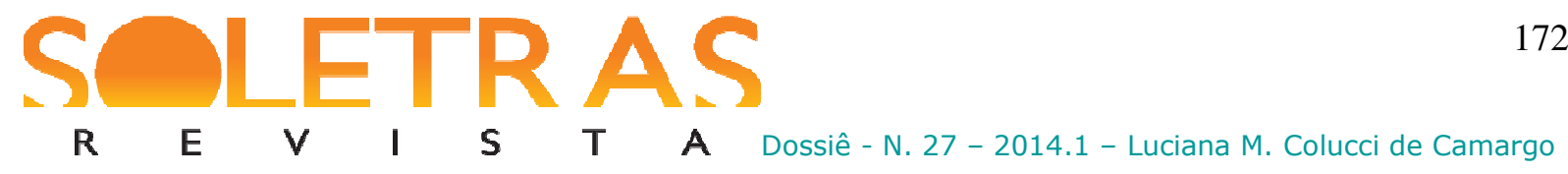

$\begin{array}{llllllll}\text { R } & \text { E } & \text { V } & \text { I } & \text { S } & \text { T } & \text { A Dossiê - N. 27-2014.1-Luciana M. Colucci de Camargo }\end{array}$

And the holy-poly toy devoured it, even though it was alive with maggots. In a corner a cabby sickened by the scene was puking; his neighbour did likewise, and in less than twenty to twenty-three seconds there was a general vomiting in the dramshop. The inn reeked with the odour of carcass and undigested drink and all that could be heard was the racket of drunken eructations, the torrents of unassimilated liquids, and perfectly involuntary farts. The owner's wife, the waiter and the waitress were all voiding the contents of their stomachs by their buccal orifices. Alone, still standing on his little bench, the artist revelled in this triumph; slowly he carried on chomping, and as maggots spilled from the corners of his mouth he would deftly catch them up again and munch on them with relish. And when he had finished this diabolical repast, the treated the company to a piece of funeral music, a de profundis firmly applied to his cheeks. The cat was removed, there was a moment of calm and they all stared at one another. God! How idiotic they looked! (GENONCEAUX, 2013, p. 39-41, grifo nosso).

Mais uma vez, Mauri e seus convivas promovem um verdadeiro banquete diabólico e macabro (diabolical repast), propiciando, sobremaneira, efeitos de estranhamento, horror e repugnância já que o gato é descrito como stinking, viscious and magotty. Após decidirem que o gato seria saboreado frio, um dos presentes (o artista) escolhe degustar a unmentionable bit, fazendo clara alusão ao pênis do felino. Para dar prosseguimento ao ritual, La Pondeuse (a anfitriã) é escolhida para a ablação do referido órgão. No encadeamento da situação, temos uma sequência de fatos que aproximam o "banquete" de uma ritualística funérea, pois o animal é colocado no chão, entre quatro velas, e os presentes formam um círculo, à moda das feiticeiras celtas, para apreciar a amputação do pênis.

Para conferir maior solenidade e propiciar um efeito de estranhamento e incredulidade à situação, taças de champagne são trazidas e todos entoam um canto pesaroso: This is now Mary's month, of all the months the fairest. Quando o artista constata que não há pênis para ser devorado, ele pede um pedaço da cauda, mais precisamente cinquenta centímetros. A apreciação daquela porção é realizada como se o artista estivesse degustando uma das iguarias mais extraordinárias do Olimpo. Os convidados, ao observarem a cena grotesca e os vermes vivos caindo pelos cantos da boca do amigo, começam a passar mal e uma avalanche de grotesquerias acontece: vômitos, líquidos de várias naturezas e flatulências involuntárias. No entanto, o artista não se deixa incomodar e termina tranquilamente sua iguaria ao som de uma música fúnebre, a de profundis. A bizarrice daquele instante é tanta que os convidados, após a retirada do que sobra do gato, olham assombrados uns para os outros. Até mesmo o narrador heterodiegético comporta-se como "intruso" no episódio e, nuançando o efeito de objetividade, expressa sua opinião: "God! How idiotic they looked!"

As considerações acima - as passagens da escolha do mobiliário, o apartamento 
$\begin{array}{llllllll}R & \text { E } & \text { V } & \text { I } & \text { S } & \text { T } & \text { A } & \text { Dossiê - N. 27-2014.1-Luciana M. Colucci de Camargo }\end{array}$

decorado como um sepulcro e a apreciação do repasto diabólico - articulam perfeitamente os gradientes sensoriais (por meio da sinestesia), a decoração (mobília, ornamentos, perfumes) que objetiva tecerem um espaço gótico que se delineia por meio de uma forte configuração imagética e sensorial, sendo, portanto, possível aproximá-lo de um ritual cuja sacralidade é às avessas e, portanto, carregado de horror e perversão. O estudioso do Simbolismo, Arthur Symons, na obra The symbolist movement in literature, empreende uma reflexão sobre a poesia de Verlaine e Baudelaire que se ajusta perfeitamente à análise que temos desenvolvido neste ensaio no que se refere ao refinamento estético-sensorial do dândi e sua intrínseca relação com o espaço. Vejamos:

There is a deliberate science of sensual perversity which has something almost monachal in its accentuation of vice with horror, in its passionate devotion to passions. Baudelaire brings every complication of taste, the exasperation of perfumes, the irritant of cruelty, the very odours and colours of corruption, to the creation and adornment of a sort of religion, in which an eternal mass is served before a veiled altar (s/d, p. 223).

Dadas essas considerações, encerramos esse tópico, reafirmando que a tessitura do espaço gótico é um signo fatal que se realiza plenamente, em termos de plano de expressão e de conteúdo, nas tramas da escritura decadentista de The Tutu validando o "peculiar" talento artístico e avant-la-lettre de Genonceaux e, ainda, o questionamento que White faz ao final de sua introdução: “(w)hat effect would it have had if it had indeed appeared in 1891, when it was written?"

\section{Considerações finais}

Para finalizar, passamos às últimas considerações deste ensaio observando que Mauri é uma personagem de dimensão ambivalente cuja única preocupação é extrair da vida toda seiva que suscite experiências sensoriais únicas. Por meio de atitudes transgressoras e grotescas, a personagem investe-se do poderio dos signos fatais do decadentismo - o dandismo, a androginia e a artificialidade como simulacro - para viver seus dias em uma espécie de rêverie carnavalizada. Para Mauri, experimentar a vida pelo avesso não é uma condição permitida apenas em um determinado momento do ano em que exista "certa autorização" para se adentrar ao submundo das estranhezas. Ao contrário, a personagem emblemática de The Tutu cria um microcosmo (seu mundo) à parte do macrocosmo (o mundo social) em que os rituais perversos e macabros fazem parte de seu cotidiano como forma de combater o tédio e o desprezo que ele sente pela burguesia da época e, em lato sensu, pela 
$\begin{array}{llllllll}R & \text { E } & \text { V } & \text { I } & \text { S } & \text { T } & \text { A } & \text { Dossiê - N. 27-2014.1-Luciana M. Colucci de Camargo }\end{array}$

raça humana em geral. Nesse sentido, Mauri se vale da qualidade de "habilíssimo decorador", de arguto esteta para criar espaços, ambientes e cenários góticos que interagem homologicamente com sua personalidade soturna.

Ampliando o efeito de sentido de estranheza para a narrativa como um "todo" com suas imagens repugnantes e hibridismo de gêneros, é possível inferir que grotesca e excessiva é a condição sine qua non não somente de Mauri, mas de The Tutu como um romance decadentista que se tivesse sido mesmo distribuído por ocasião de sua primeira publicação em 1891, certamente teria escandalizado a sociedade burguesa parisiense do século XIX e enviado Genonceaux para a prisão.

Expostas essas reflexões e considerando o seu contexto fin-de-siécle - histórico, social e literariamente - acreditamos que Genonceaux seja mais um emérito membro da sociedade dos poètes maudits uma vez que se aproxima do arquétipo maldito tão bem corporificado por escritores como Poe, Baudelaire, Wilde e Huysmans que se voltam "para as regiões misteriosas do obscuro, da sordidez e do satânico, tornando-se, por fim, os poetas do abismo" (CAMARANI; CAMARGO, 2014, p. 24).

Portanto, essa trama de encruzilhadas estéticas, formais e temáticas tão peculiares frisa a relevância de The Tutu, morals of the Fin de Siècle para a contemporaneidade, justificando, assim, o resgate dessa obra da obscuridade literária para que sejam realizados estudos críticos aprofundados acerca desta narrativa que é considerada pela crítica como sendo uma das obras mais estranhas, misteriosas e fascinantes já escritas, “[...] a sort of ultimate decadent novel” (GENONCEAUX, 2013, contracapa).

\section{Referências bibliográficas:}

ACKERMAN, Diane. Una historia natural de los sentidos. Barcelona: Anagrama, 2009.

BALZAC, Honoré de; BAUDELAIRE, Charles; BARBEY, D’Aurevilly. Manual do dândi: a vida com estilo. Trad. Tomaz Tadeu. São Paulo: Autêntica, 2009.

BARROS, Fernando Monteiro de. A poesia decadentista de Victor Silva. In: COUTINHO, Luiz Edmundo Bouças; FARIA, Flora de Paoli. Faces rituais da poesia. Rio de Janeiro: UFRJ; FBN; Confraria do Vento; Brasília: CNPq, 2010, p.125-137.

BAUDELAIRE, Charles. Poesia e prosa. Rio de Janeiro: Nova Aguilar, 2006.

BORGES FILHO, Ozíris. Espaço \& literatura: introdução à topoanálise. Franca, SP: Ribeirão Gráfica e Editora, 2007. 
$\begin{array}{llllllll}\text { R } & \text { E } & \text { V } & \text { I } & \text { S } & \text { T } & \text { A } & \text { Dossiê - N. 27-2014.1-Luciana M. Colucci de Camargo }\end{array}$

CAMARANI, A. L. e CAMARGO, L. M. C. Poe, Baudelaire, Huysmans: dândis e Malditos. In: Revista Estação Literária: Programa de Pós-graduação em Letras da Universidade Estadual de Londrina, 2014, Londrina.

CAMARGO. Luciana Moura Colucci de. A filosofia do mobiliário: por uma poética do espaço gótico. In: Abralic: Associação Brasileira de Literatura Comparada, 2008, São Paulo. Eletrônico. Abralic: Abralic, 2008.

EDWARDS, Justin; GRAULUND, Runde. Grotesque. New York: Routledge, 2013.

GENONCEUAX, Léon. The Tutu, morals of the Fin de Siècle. London: Atlas, 2013.

HUYSMANS, Joris Karl. Às avessas. Trad. José Paulo Paes. São Paulo: Companhia das Letras, 1987.

MUCCI, Latuf Isaias. Ruína \& simulacro decadentista. Rio de Janeiro: Tempo Brasileiro, 1990.

PALACIO, Jean de. Le silence du texte: poétique de la décadence. Louvain; Paris: Peeters, 2003.

PASCAL, Pia. La Quinzaine Littéraire. Acesso 28 jan 2014. Disponível em http://laquinzaine.wordpress.com/2011/04/18/un-de-des-inventeurs-maldoror/

SYMONS, Arthur. The Symbolist Movement in Literature. New York: E. P. Dutton \& Company, s/d.

WORDSWORTH, William; COLERIDGE, Samuel Taylor. Preface to the Lyrical Ballads. Acesso 01 fev 2014. Disponível em http://www.bartleby.com/39/36.html.

\title{
The Tutu, morals of the Fin de Siècle: reception and conjectures on a decadent novel under the fatal signs of the gothic and the dandism
}

\begin{abstract}
This essay examines the literary work The Tutu, morals of the Fin de Siècle (1891), by the French writer and editor Genonceaux Léon (1856-1905?), under the perspective of the decadent and gothic aesthetic. Under the bias of the fatal signs of Decadentism - dandyism, androgyny and artificiality as a simulacrum - The Tutu narrates the eccentric adventures of the young dandy Maurice Noirof in the quest for rare sensations that confront the social, religious and sexual codes in Paris in the late nineteenth century. For its decadent nature and macabre tone, The Tutu naturally raises a dialogue with the gothic and therefore values the space as relevant to the narrative structure of this novel. It is precisely the peculiar connection with Noirof that the setting becomes a gloomy and dismal atmosphere in which fear, anguish, monstrous and the search for exotic experiences define the plot. So, all these aesthetic, formal and thematic injunctions highlights the relevance of The Tutu for this contemporary times, thus justifying a detailed study of this narrative that is considered by critics as one of the




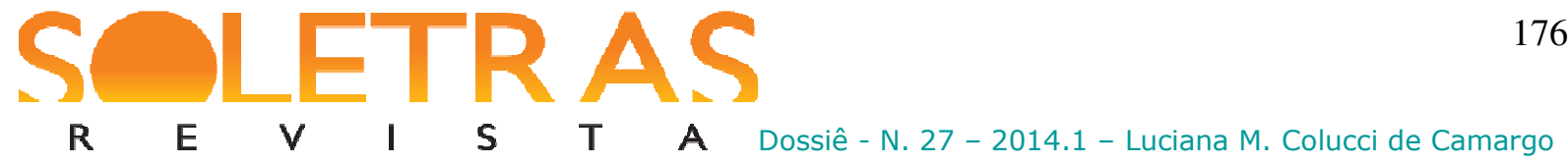
strangest, mysterious and fascinating works ever written, a "sort of ultimate decadent novel", according to Genonceaux.

Key words: The Tutu. Decadentism. Dandy. Gothic. Space.

Recebido em: 15 de maio de 2014.

Aprovado em: 25 de agosto de 2014. 